\title{
Sodium Selenite Improves The Therapeutic Effect Of BMSCs Via Promoting The Proliferation And Differentiation, Thereby Promoting The Hematopoietic Factors
}

This article was published in the following Dove Press journal: OncoTargets and Therapy

\author{
Dongmei Yan ${ }^{1, *}$ \\ Botao Tang ${ }^{2, *}$ \\ Lixin Yan $^{3}$ \\ Lei Zhang' \\ Meijuan Miao' \\ Xi Chen ${ }^{4}$ \\ Guangyi Sui ${ }^{5}$ \\ Qi Zhang' \\ Daoyuan Liu' \\ Hui Wang (1D'
}

'Department of Blood Transfusion, The Second Affiliated Hospital of Harbin Medical University, Harbin, People's Republic of China; ${ }^{2}$ Department of Cardiology, Heilongjiang Red Cross Hospital, Harbin, People's Republic of China; ${ }^{3}$ Department of Laboratory Medicine, The Second Affiliated Hospital of Harbin Medical University, Harbin, People's Republic of China; ${ }^{4}$ Department of Hematology, The Second Affiliated Hospital of Harbin Medical University, Harbin, People's Republic of China;

${ }^{5}$ Ethics Committee, The Tumor Hospital Affiliated to Harbin Medical University, Harbin, People's Republic of China

*These authors contributed equally to this work

Correspondence: Hui Wang

Department of Blood Transfusion, The Second Affiliated Hospital, Harbin Medical University, Xuefu Road No. 246, Nangang District, Harbin, Heilongjiang Province,

People's Republic of China

Tel +86-45I-86605I34

Email wanghui@hrbmu.edu.cn
Purpose: Sodium selenite $\left(\mathrm{Na}_{2} \mathrm{SeO}_{3}\right)$ has been known to restore the antioxidant capacity of bone marrow mesenchymal stem cells (BMSCs), reduce the production of reactive oxygen species (ROS) in the cells, and promote cell proliferation and inhibit cell apoptosis. However, it is still not clear whether selenium can mediate the differentiation and inhibit the induced hemagglutination of BMSCs. In this study, we attempted to explore the effect of $\mathrm{Na}_{2} \mathrm{SeO}_{3}$ on these aspects of BMSCs.

Methods: We evaluated the fate of the MSCs isolated from the bone marrow of mice by studying their differentiation and proliferation after treatment with $\mathrm{Na}_{2} \mathrm{SeO}_{3}$. We also simultaneously evaluated the coagulation reaction induced by $\mathrm{Na}_{2} \mathrm{SeO}_{3}$-treated BMSCs in vitro.

Results: While the mice-derived BMSCs expressed CD44, CD73, CD90, and CD105, they did not express CD45. The morphology of the derived cells was homogeneously elongated. These results showed that the isolated cells are indeed BMSCs. We found that $0.1 \mu \mathrm{M}$ and 1 $\mu \mathrm{M}$ of $\mathrm{Na}_{2} \mathrm{SeO}_{3}$ promoted the proliferation and apoptosis of BMSCs, respectively. This showed that $\mathrm{Na}_{2} \mathrm{SeO}_{3}$ can be toxic and exert certain side effects on the BMSCs. The results of the osteogenic and adipogenic assay showed that $0.1 \mu \mathrm{M} \mathrm{Na} \mathrm{NeO}_{3}$ could significantly promote the osteogenic and adipogenic differentiation of BMSCs by upregulating the lipid factors (LPL and PPRAG) and osteogenic factors, RUNX2, COL1, and BGP, in a concentration-dependent manner. Coagulation experiments in animals (mice and rats) revealed that $\mathrm{Na}_{2} \mathrm{SeO}_{3}$ can reduce the coagulation time of BMSCs in a concentration-dependent manner, which is related to the high expression of hematopoietic factors (SDF-1 $\alpha$, GM-CSF, IL-7, IL8, IL-11, and SCF).

Conclusion: $\mathrm{Na}_{2} \mathrm{SeO}_{3}$ promotes the proliferation and differentiation as well as reduces the coagulation time of BMSCs, and this effect might enhance the therapeutic effect of BMSCs. Keywords: sodium selenite, BMSCs, proliferation, differentiation, coagulation factors, clotting time

\section{Introduction}

Bone marrow mesenchymal stem cells (BMSCs) are precursors of bone marrow stromal cells (including adipocytes, fibroblasts, and endothelial cells). It is an important component of the hematopoietic microenvironment in vivo as it plays a crucial role in the formation of hematopoietic microenvironment and the regulation of hematopoiesis. Postnatal "mesenchymal stem cells" are derived from bone marrow stromal cells, which are non-hematopoietic adherent cells. Although 
different tissue-derived mesenchymal stem cells do not have a common embryonic origin or pedigree, they all have the characteristics of tissue-specific stem/progenitor cells. The differentiation ability of mesenchymal stem cells (MSCs) varies based on their tissue of origin. ${ }^{1}$ Although most adults possess tissue-specific stem cells, they have limited ability to transform into other cell types. $^{2}$

MSCs regulate the proliferation and homing of hematopoietic stem cells by secreting multiple adhesion molecules, cytokines, and cell interactions. Animal and clinical trials have shown that the combined effect of MSCs in hematopoietic stem cell transplantation could expedite the hematopoietic stem cell implantation by rapidly recovering the neutrophils and platelets as well as reducing the incidence and severity of graft rejection and graft versus host disease (GVHD). Therefore, MSCs have good research value and prospective applications in the field of hematopoietic stem cell transplantation. ${ }^{3-6}$

While MSCs were initially identified in the bone marrow, they can also be isolated from various tissues, such as umbilical cord blood, amniotic fluid, endometrium, peripheral blood, and lungs. ${ }^{7}$ At present, based on the research on bone marrow hematopoietic microenvironment, it can be divided into two parts, osteoblast cells and vascular area (located near the sinus gap). Osteoblasts are generally considered to be important components of bone marrow hematopoietic microenvironment and play a major role in the regulation of numbers of hematopoietic stem cells. BMSCs have become a therapeutic tool for the treatment of many diseases due to their role in regulating immune response and promoting endogenous regeneration. Intravascular injection of BMSCs has been proved to be an effective treatment for autoimmune diseases, ${ }^{8,9}$ vascular diseases, ${ }^{10}$ and diabetes. ${ }^{11}$ However, recent studies have found that MSCs can be incompatible with receptor blood. In in vitro conditions, it has been seen that MSCs can express several tissue coagulation factors such as collagen 1A and fibronectin 1 and the coagulation cascade can be induced when MSCs were transfused into the blood. $^{12,13}$ However, the inflammatory reaction mediated by hepatocytes and lung cells could affect the survival and function of the transplanted cells ${ }^{13}$ and also seriously hamper the therapeutic effect of MSCs. Therefore, reduction of the coagulation reaction induced by the BMSCs is an effective way to improve its therapeutic effect in order to ensure the efficacy of the treatment with BMSCs.
Selenium ( $\mathrm{Se}$ ) is an essential trace element found in mammals, and it is a known antioxidant. ${ }^{14}$ There are about 25 selenium-containing proteins that are involved in the antioxidant activity in humans. The main forms of selenium are divided into organic selenium (such as $\mathrm{CH}_{3} \mathrm{SeH}$, seleno-L-methionine (SeMet)) and inorganic selenium (such as sodium selenite $\left(\mathrm{Na}_{2} \mathrm{SeO}_{3}\right)$ ). $\mathrm{Na}_{2} \mathrm{SeO}_{3}$ is the most common reagent that is used as a Se supplement for clinical use. It was found that both $\mathrm{CH}_{3} \mathrm{SeH}$ and $\mathrm{Na}_{2} \mathrm{SeO}_{3}$ could significantly inhibit the proliferation of A549 cells, increase the percentage of cellular apoptosis, induce blocking of the G0/G1 checkpoint, and inhibit the cell cycle process by suppressing the formation of cellular glutathione (GSH). ${ }^{15}$ Se also induces the telomerase activity of human umbilical cord mesenchymal stem cells and mediates the expression of the tumor suppressor gene, p53. ${ }^{16}$ Few studies have pointed out that selenoproteins can promote the differentiation of bone marrow cells and bone marrow mononuclear cells. ${ }^{17-19}$ In addition, sodium selenite can restore the antioxidant capacity of BMSCs, reduce the production of ROS in cells, promote cell proliferation, and inhibit cell apoptosis. ${ }^{20}$ However, there is no clear evidence showing whether Se mediates BMSC differentiation and inhibit the hemagglutination induced by BMSCs.

We hypothesized that $\mathrm{Na}_{2} \mathrm{SeO}_{3}$ can promote the proliferation and differentiation of BMSCs as well as inhibit the expression of coagulation factors and promote the production of hematopoietic factors from these cells, and thus, improve the therapeutic effect of BMSCs. In this study, the first attempt was to isolate MSCs from the bone marrow of mice. Then, after $\mathrm{Na}_{2} \mathrm{SeO}_{3}$ intervention, we evaluated the differentiation and proliferation of BMSCs as well as the coagulation reaction caused by MSCs in vitro. In this study, we elucidated the inhibitory effect of $\mathrm{Na}_{2} \mathrm{SeO}_{3}$ on the blood coagulation induced by BMSCs, and this provides a novel approach for improving the treatment using BMSCs by promoting the hematopoietic function of the hematopoietic stem cells.

\section{Materials And Methods Isolation And Identification Of BMSCs}

We purchased 8- to 10-week-old clean grade healthy Sprague Dawley (SD) rats from Hubei Provincial Center for Disease Control, No. 42000600019947 and 4- to 6week-old clean grade healthy mice from Hubei Provincial Center for Disease Control, No. 42000600019904. After 
sacrificing the mice using cervical dislocation, the bodies were soaked in $75 \%$ ethanol solution for 10 mins. The bilateral femur and tibia without attached muscles were removed on a sterilized worktable. The femur and tibia were flushed thrice using sterile PBS (Solarbio, Beijing, China) and the bone marrow cavity was exposed after cutting off the epiphysis ends. A small amount of serumfree DMEM-LG (Hyclone, LA, USA) was used to rinse the medullary cavity, and the bone marrow was placed on the Petri dish. Then, 7 needle was used to repeatedly blow on the bone marrow cell suspension to make single cell suspension. The suspension was centrifuged at $250 \times \mathrm{g}$ for 10 mins, the supernatant was discarded and a small amount of DMEM-LG was added to the pellet. In another $15 \mathrm{~mL}$ centrifuge tube, Percoll solution (density $1.073 \mathrm{~g} / \mathrm{mL}$, Solarbio, Beijing, China) was added to equal volume of the bone marrow cell suspension. Then, the bone marrow cell suspension was slowly added to the surface of the separation liquid with a pipette and then centrifuged at $600 \times \mathrm{g}$ for 30 mins. After centrifugation, the suspension was divided into four layers from top to bottom. The second layer of annular Lactobacillus White Lymphocyte layer was carefully separated into another $15 \mathrm{~mL}$ centrifuge tube with a sucker. Following that, $10 \mathrm{~mL}$ DMEM-LG mixed cells were added, the mixture was centrifuged at $250 \times \mathrm{g}$ for 10 mins, and supernatant was discarded. Total medium containing 15\% fetal bovine serum and 1\% DMEM-LG were added to $4 \times 10^{6}$ cells $/ \mathrm{mL}$ and were inoculated in a $25 \mathrm{~cm}^{2}$ tissue culture flask. After incubation at $37^{\circ} \mathrm{C}$ and $5 \% \mathrm{CO}_{2}$, the non-adherent cells were removed after $2 \mathrm{~d}$. The morphological changes were observed under a microscope (TS100-F, Nikon, Tokyo, Japan). All the experiments were conducted in accordance with the National Institute of Health guidelines and were approved by the Second Affiliated Hospital of Harbin Medical University (Medical ethics committee of the Second Affiliated Hospital of Harbin Medical University).

The cells were digested with $0.25 \%$ trypsin (Solarbio, Beijing, China) and a single cell suspension was prepared. The supernatant was discarded after centrifuging at $1000 \times \mathrm{g}$ for 5 mins, and, then the pellet was washed twice with PBS buffer. The cell count was measured, and the cell density was calculated to be $1 \times 10^{6}$ cells $/ \mathrm{mL}$. Further, $100 \mu \mathrm{L}$ of single cell suspension was added to six separate Eppendorf tubes, and the tubes were labeled according to the respective antibody. Into these six tubes, we added $2 \mu \mathrm{L}$ each of the following FITC conjugated antibodies: anti-CD44 (MA517872, eBioscience, Thermo Fisher Scientific, MA, USA),
anti-CD73 (11-0739-42, eBioscience, Thermo Fisher Scientific, MA, USA), anti-CD90, anti-CD105 (MA119594, eBioscience, Thermo Fisher Scientific, MA, USA), and anti-CD45 (11-9459-42, eBioscience, Thermo Fisher Scientific, MA, USA), andthe last tube was used as blank control. Then, $400 \mu \mathrm{L}$ of buffer solution was added to the tubes and they were kept at $4^{\circ} \mathrm{C}$ in the dark. The samples were detected by the flow cytometry. The results were analyzed using the CXP analysis software (BECKMAN, CA, USA).

\section{The Proliferation Of BMSCs Was Detected By MTT}

The logarithmic phase cells were collected to 96-well plates and $180 \mu \mathrm{L}$ per hole (cell concentration $5 \times 10^{3}$ cell/hole); $100 \mu \mathrm{L}$ culture liquid as blank control. Then, the well plates were incubated at $37^{\circ} \mathrm{C}$ overnight. Experimental grouping: $\mathrm{Na}_{2} \mathrm{SeO}_{3}$ (sigma, Beijing, China) concentration $0 \mu \mathrm{M}, 0.01 \mu \mathrm{M}, 0.1 \mu \mathrm{M}$, and $1 \mu \mathrm{M}$, processing time: $1 \mathrm{~d}, 2 \mathrm{~d}, 3 \mathrm{~d}$, and $5 \mathrm{~d}$. The cell culture plates of different groups were removed; $20 \mu \mathrm{L}$ MTT (Beyotime, Shanghai, China) solution $(5 \mathrm{mg} / \mathrm{mL})$ was added to each hole, and then continued to incubate for $4 \mathrm{hrs}$. After the supernatant was sucked out, $150 \mu \mathrm{L}$ DMSO (Beyotime, Shanghai, China) solution was added to each hole and oscillated at low speed for 10 mins on the shaking table. The absorbance value of each hole was measured at 490 $\mathrm{nm}$ by ELISA assay.

\section{The Apoptosis Rate Of BMSCs Was Detected By Hochest Staining And Flow Cytometry}

After $2 \mathrm{~d}$ treatment, the cells were fixed with $4 \%$ paraformaldehyde (Beyotime, Shanghai, China) for 10 mins. The fixed solution was washed with PBS solution for 2 times. A small amount of Hoechst 33258 dye solution (Solarbio, Beijing, China) was added to cover the sample for 5 mins at room temperature $\left(25^{\circ} \mathrm{C}\right)$. After removing the dye solution, it was washed with PBS 3 times. Then the cell sample was placed under the fluorescence microscope for observation. When apoptotic cells were observed, the nuclei of apoptotic cells were densely stained or fragmental. Then Flow Cytometry assay was used to detect the apoptosis rate of BMSCs. After washing the adherent BMSCs with PBS solution, $0.25 \%$ trypsin digestion liquid (containing EDTA) was added to BMSCs to digestive cells at room temperature $\left(25^{\circ}\right.$ C). Cells were collected after centrifuging at $1000 \times \mathrm{g}$ for 5 
mins, and PBS was used to gently suspend the cells . Binding buffer was added to $1 \times 10^{6}$ cells $/ \mathrm{mL}$, then centrifuged at $300 \times \mathrm{g}$ for $10 \mathrm{mins}$. After adding $5 \mu \mathrm{L}$ Annexin V-FITC into $100 \mu \mathrm{L}$ cells suspension, the mix was kept for $10 \mathrm{mins}$ at room temperature. Then, $5 \mu \mathrm{L}$ PI was added at room temperature for 5 mins, followed by $300 \mu \mathrm{L}$ binding buffer. Apoptotic cells were detected by flow cytometry within $1 \mathrm{hr}$.

\section{Detection Of Lipid (Adipogenic)-Induced Differentiation}

The fourth generation of BMSCs in the logarithmic growth period was digested with $0.25 \%$ trypsin, and the digested cells with $1 \mathrm{~mL}$ complete medium were inoculated in 12well plates with $0.1 \%$ gelatin in advance by the density of $1 \times 10^{5} \mathrm{cell} / \mathrm{cm}^{2}$ cells. The cells were cultured in incubators at $37^{\circ} \mathrm{C}$ and $5 \% \mathrm{CO}_{2}$. When the cell fusion degree is about $80 \%$, the complete medium in the hole was removed. Then, $1 \mathrm{~mL}$ lipid-induced complete medium A solution was added into the 12 -well plates for $2 \mathrm{~d}$. The A solution was removed with PBS solution, and then the lipid-induced complete medium B solution was added for maintenance. After $24 \mathrm{hrs}$, B solution was removed and then $1 \mathrm{~mL}$ lipid-induced complete medium A solution was added into the plates for $2 \mathrm{~d}$. It was replaced for 3-5 times. Until there is a large oil droplet in the complete medium, then the cells were subsequently stained. With the end of adipogenic differentiation, the adipogenic differentiation medium was removed from 12-well plates and washed 2 times with $1 \times$ PBS solution. A total of $1 \mathrm{~mL} 4 \%$ neutral formaldehyde solution was added to each hole for 30 mins. Then, $1 \mathrm{~mL}$ of oil red $\mathrm{O}$ dye was added to each hole for 30 mins. After washing with $1 \times$ PBS for 3 times, the culture plate was placed under a microscope to observe the effect of fat dyeing.

\section{Detection Of Osteogenesis}

\section{(Chondrogenic)-Induced Differentiation}

The fourth generation of BMSCs in the logarithmic growth period was digested with $0.25 \%$ trypsin, and the digested cells with $1 \mathrm{~mL}$ complete medium were inoculated in 12 -well plates with $0.1 \%$ gelatin in advance by the density of $1 \times 10^{5}$ cell $/ \mathrm{cm}^{2}$ cells. The cells were cultured in incubators at $37^{\circ} \mathrm{C}$ and $5 \% \mathrm{CO}_{2}$. When the cell fusion degree is about $80 \%$, the complete medium in the hole was removed. Then, $1 \mathrm{~mL}$ fresh bone-induced complete medium solution was added into the 12-well plates every 3 times. After 2 weeks of induction, the morphology and growth of the cells were observed. Calcareous staining with alizarin red method: $4 \%$ polyoxymethylene was used to fix the cells for 15 mins, then it was washed for 5 mins using distilled water. The cells were dyed with alizarin red dye for 2-5 mins, washed quickly using distilled water, dyed 20-30 s with green water solution, washed with $0.2 \%$ glacial acetic acid solution. Then it was dehydrated quickly with $95 \%$ alcohol and anhydrous ethanol, sealed with neutral gum. Alkaline phosphatase (Gomorimodified calcium cobalt method) staining: $4 \%$ polyoxymethylene was used to fix the paraffin sections for 15 mins, then it was dewaxed. The ALP incubated solution was added into the wet box and the sections were incubated in cobalt nitrate solution at $37^{\circ} \mathrm{C}$ for $5 \mathrm{mins}$, the sections were put into the vulcanizing working fluid for 2 mins and washed with distilled water for 10 mins. Paraffin sections were dehydrated, transparent, and gum sealed.

\section{The Expression Of Osteogenic Factors Were Detected By RT-qPCR}

A total of $1 \times 10^{5}$ BMSCs were seeded on 6-well plates; it was treated with $0 \mu \mathrm{M}, 0.01 \mu \mathrm{M}, 0.1 \mu \mathrm{M}, 1 \mu \mathrm{M} \mathrm{Na} \mathrm{SeO}_{3}$ for 48 hrs respectively, and the cells were collected. $1 \mathrm{~mL}$ Trizol was added in plates and then homogenated for $20 \mathrm{~s}$, immediately put on ice to incubate for 5 mins, centrifuged at $12,000 \times \mathrm{g}$ for $10 \mathrm{mins}$ at $4^{\circ} \mathrm{C}$. The supernatant was diverted to a clean $1.5 \mathrm{~mL}$ centrifuge tube, added with $200 \mu \mathrm{l}$ chloroform, stood for 2 mins then centrifugated with 12,000 $\times \mathrm{g}$ for 10 mins at $4{ }^{\circ} \mathrm{C}$. After precipitation with isopropanol of equal volume, $75 \%$ ethanol was rinsed and precipitated for 2 times and dried at room temperature for 10 mins. $40 \mu \mathrm{L}$ DEPC of water was added to dissolve the extracted total RNA. cDNA chain was synthesized by using a reverse transcription of Advantage ${ }^{\circledR}$ RT-for-PCR Kit (TAKARA, Dalian, China). Then SYBR ${ }^{\circledR}$ Premix Ex Taq ${ }^{\mathrm{TM}}$ II (Tli RNaseH Plus) (TAKARA, Dalian, China) was used to analyze the relative expression of mRNA. The data were analyzed by software: qbase plus 2.0. Reaction procedure: $95^{\circ} \mathrm{C}, 3 \mathrm{mins} ; 95^{\circ} \mathrm{C}, 5 \mathrm{~s}$; $56^{\circ} \mathrm{C}, 10 \mathrm{~s} ; 72^{\circ} \mathrm{C}, 25 \mathrm{~s} ;\left(39\right.$ cycles) $65^{\circ} \mathrm{C}, 5 \mathrm{~s} ; 95^{\circ} \mathrm{C}, 50 \mathrm{~s}$. The involving primers were LPL (Forward primer: 5'TCCTGATGACGCTGAT-3'; Reversed primer: 5'CCTCCATTGGGATAAA-3'), PPARG (Forward primer: 5'-GAACCTGCATCTCCACC-3'; Reversed primer: 5'- 
CACAGACTCGGCACTCA-3'), RUNX2 (Forward primer: 5'-CTGGCGGTGCAACAAGA-3'; Reversed primer: 5'ACAGCGGAGGCATTTCG-3'), and GAPDH (Forward primer: 5'-CCTTCCGTGTTCCTAC-3'; Reversed primer: 5'GACAACCTGGTCCTCA-3').

\section{The Osteogenic Factor Proteins Were Detected By Western Blot}

A total of $1 \times 10^{5}$ BMSCs were seeded on 6-well plates, it was treated with $0 \mu \mathrm{M}, 0.01 \mu \mathrm{M}, 0.1 \mu \mathrm{M}, 1 \mu \mathrm{M} \mathrm{Na}_{2} \mathrm{SeO}_{3}$ for $48 \mathrm{hrs}$ respectively, and the cells were collected. After adding appropriate pre-cooling $1 \times$ PBS to wash the cells for 2 times, PBS solution was removed, then adding lysate containing protease and phosphatase inhibitor into the plates, cracking cells fully at $4^{\circ} \mathrm{C}$, scraping cells into 1.5 $\mathrm{mL}$ EP tube. The plates were then heated for $10 \mathrm{mins}$ at $95^{\circ} \mathrm{C}$, and centrifuged at $12,000 \times \mathrm{g}$ for 10 mins. Enhanced BCA Protein Assay Kit (Beyotime, Shanghai, China) was used for protein quantification. SDS-PAGE gel was prepared by electrophoretic separation of protein and then transferred to PVDF membrane. 5\% skimmed milk powder was used to close the proteins and it was incubated at $4^{\circ} \mathrm{C}$ for overnight. According to the instruction, the antibody was diluted to the desired concentration and then incubated at $4{ }^{\circ} \mathrm{C}$ for overnight. The involved antibodies LPL (1:1000, ab21356), PPRAG (1:500, ab45036), RUNX2 (1:1000, ab23981), and GAPDH (1:2500, ab9485) were purchased from Abcam (Abcam, Cambridge, MA, USA). Then, the membrane was washed with PBST for 3 times. The horseradish peroxidaselabeled goat anti-rabbit IgG (1:5000, ab6721) and horseradish peroxidase-labeled goat anti-mouse IgG (1:5000, ab6789) were purchased from Abcam (Abcam, Cambridge, MA, USA). The secondary antibodies were incubated at $4{ }^{\circ} \mathrm{C}$ for overnight. The membrane was placed in the darkroom, then the mixed solution of the ECL luminescent liquid $\mathrm{A}$ and $\mathrm{B}$ according to the introduction was added on it and fully contact the front side of the membrane. The membrane was detected in a fully automated chemiluminescence analyzer.

\section{Detection Of Clotting Time}

The $2 \mathrm{~mL}$ whole blood of mice and rats was collected respectively using the anticoagulant tube of citric acid and mixed well. A mixture of $10 \mu \mathrm{L}$ cell suspension, $90 \mu \mathrm{L}$ anticoagulant, and $7 \mu \mathrm{L} \mathrm{CaCl}_{2}(0.2 \mathrm{M})$ were used as control vectors with equal volume of PBS mixed. Then the mixed solution was put in $37^{\circ} \mathrm{C}$ water bath and mix several times. Observe fibrin filament and blood clots regularly, repeat 3 times. A total of $0,5,10,20$, and $40 \times 10^{4}$ BMSCs were seeded on 6-well plates and treated with $0.1 \mathrm{M} \mathrm{Na}_{2} \mathrm{SeO}_{3}$ for $48 \mathrm{hrs}$. The pro-coagulant activity of BMSCs was determined by mixing $10 \mu \mathrm{L}$ cell suspension, $90 \mu \mathrm{L}$ anticoagulant, and $7 \mu \mathrm{L} \mathrm{CaCl}_{2}(0.2 \mathrm{M})$, and the time of blood clot formation was measured. The specific detection method of coagulation time is to collect the treated blood in each hole of the capillary glass tube. Time is calculated starting with blood flowing into the capillary. After the blood is filled, the capillaries are removed and placed on the table. Each $30 \mathrm{~s}$, two capillaries are broken about $0.5 \mathrm{~cm}$ and slowly pulled to the left and right to observe whether there are blood coagulation wires at the broken place. The coagulation time lasts until the blood coagulation wires appear.

\section{The Factors Of Clotting Time Were Detected By ELISA}

A total of $1 \times 10^{5}$ BMSCs were seeded on 6-well plates; it was treated with $0 \mu \mathrm{M}, 0.01 \mu \mathrm{M}, 0.1 \mu \mathrm{M}$, and $1 \mu \mathrm{M}$ $\mathrm{Na}_{2} \mathrm{SeO}_{3}$ for $48 \mathrm{hrs}$, and the cells were collected. The levels of GM-CSF (A0130), IL-8 (A0109), SCF (A0184), and alkaline phosphatase (A059) were detected by ELISA kits (Nanjing Jiancheng Bioengineering Institute, Nanjing, China). The levels of IL-7 (69-99929), IL-11 (69-99848), and SDF-1 $\alpha$ (69-21014) were detected by ELISA kits (MSK, Wuhan, China).

\section{Statistical Analysis}

All data were analyzed using SPSS 19.0 statistical software (IBM, NY, USA). All values are expressed as the mean \pm standard deviation. Student's $t$-test was used to analyze the results, followed by Dunnett's or Duncan's test for multiple comparisons. All experiments were performed in triplicate. A P value less than 0.05 was considered significant difference.

\section{Results}

\section{Identification Of BMSCs In Mice}

According to the International Society for Stem Cell Research (ISSCR), MSCs are usually characterized based on the following three criteria: 1) plastic adhesion ability in standard culture; 2) non-expression or low expression of CD45, CD34, CD14, CD11b, CD79a, CD19, and HLADR and high expression of CD105, CD73, and CD90; and 3) ability to differentiate into osteoblasts, adipocytes, and 
chondrocytes in vitro. ${ }^{21}$ Investigation of the morphology of the isolated cells showed that they displayed homogeneous elongated (Figure 1A) structures, and the BMSCs expressed CD44, CD73, CD90, and CD105, but not CD45. These results showed that we successfully separated the BMSCs from the mice bone marrow (Figure 1B).

\section{Detection Of Proliferation And Apoptosis Of BMSCs}

MTT assay was performed to detect the effect of different concentrations of $\mathrm{Na}_{2} \mathrm{SeO}_{3}$ on the proliferation of BMSCs (Figure 2A). The results showed that with increase in the $\mathrm{Na}_{2} \mathrm{SeO}_{3}$ concentration, the proliferation rate of BMSCs increased. However, on the third day of $\mathrm{Na}_{2} \mathrm{SeO}_{3}$ treatment, only $0.1 \mu \mathrm{M} \mathrm{Na} \mathrm{SeO}_{3}$ could promote the proliferation of BMSCs. Further, the effect of different concentrations of $\mathrm{Na}_{2} \mathrm{SeO}_{3}$ on BMSCs in inducing apoptosis was evaluated (Figure $2 \mathrm{~B}$ and $\mathrm{C}$ ). The results showed that $1 \mu \mathrm{M} \mathrm{Na} \mathrm{SeO}_{3}$ could significantly promote the apoptosis of BMSCs, while the $0.01 \mu \mathrm{M}$ and $0.1 \mu \mathrm{M} \mathrm{Na}_{2} \mathrm{SeO}_{3}$ had little effect on the apoptosis of BMSCs. In summary, $0.1 \mu \mathrm{M} \mathrm{Na} \mathrm{SeO}_{3}$ promoted the proliferation, while $1 \mu \mathrm{M}$ $\mathrm{Na}_{2} \mathrm{SeO}_{3}$ induced apoptosis in BMSCs. This suggests that $\mathrm{Na}_{2} \mathrm{SeO}_{3}$ has toxic side effects, which is consistent with previous studies. $^{21}$ Therefore, for the subsequent trials, only $0.1 \mu \mathrm{M} \mathrm{Na}_{2} \mathrm{SeO}_{3}$ was used to treat BMSCs.

\section{Detection Of BMSCs Osteogenic And Adipogenic Differentiation}

The processes of osteogenic and adipogenic differentiation of MSCs in normal bone marrow are known to be in dynamic equilibrium. Any imbalance in the

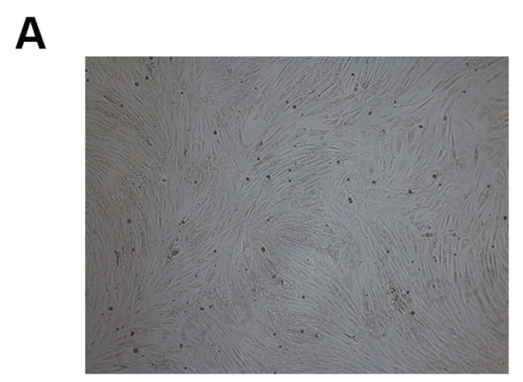

$40 x$

B
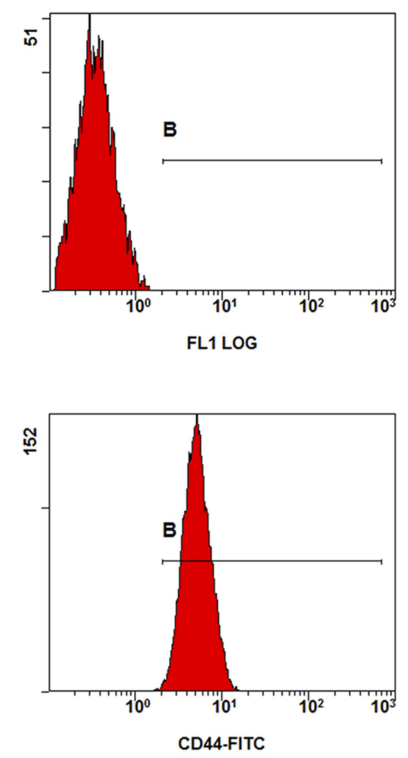

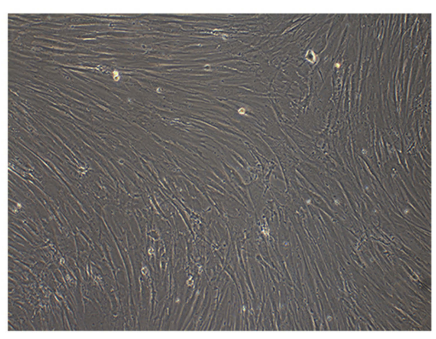

$100 x$

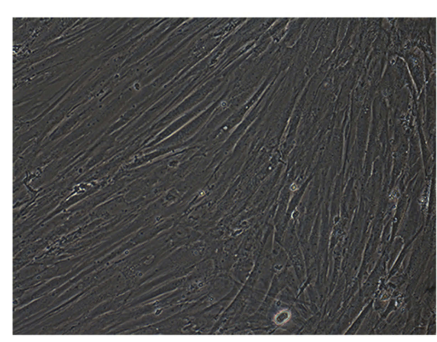

$200 x$
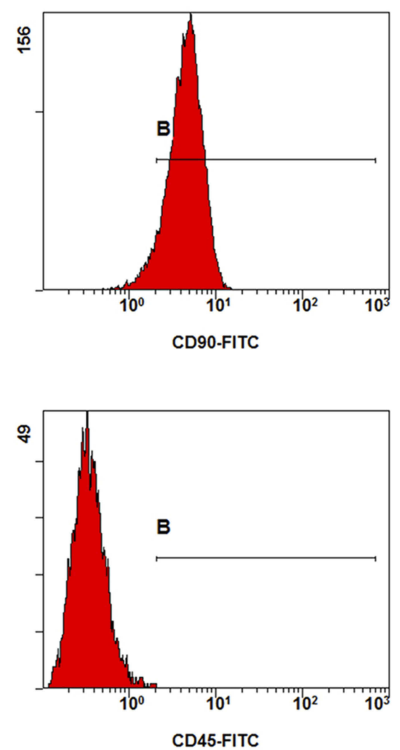
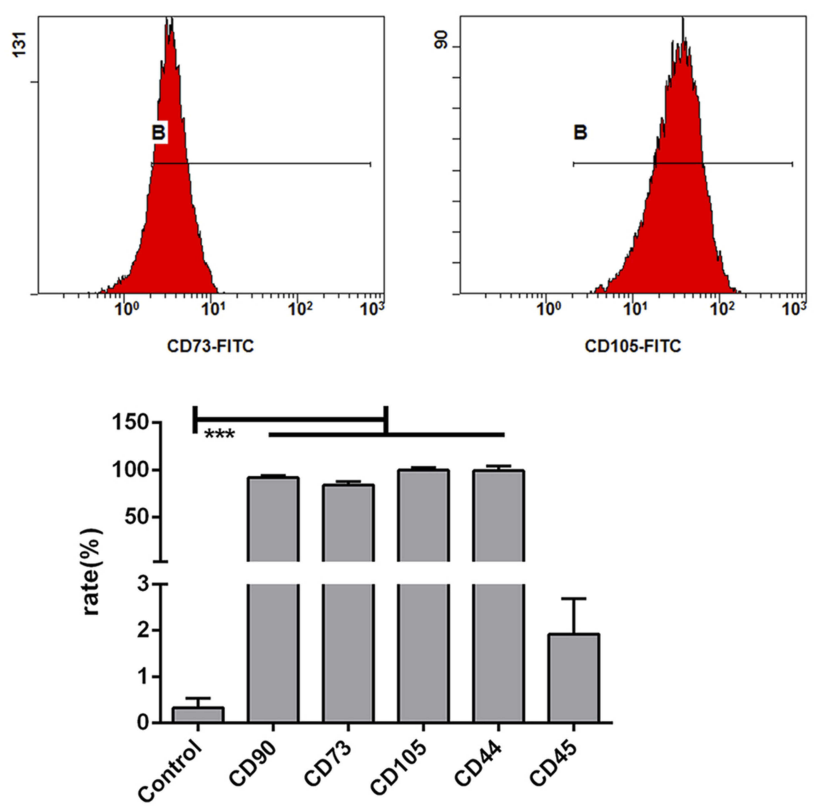

Figure I Identification of BMSCs in mice. Morphological observations at different magnifications (40×, I00×, and 200×) showed that the bone marrow stem cells (BMSCs) isolated from mice were homogeneously elongated (A). Various cell surface markers of BMSCs were detected on the cells, including CD90, CD73, CDI05, CD44, and CD45 (B). The values are from triplicate determinations. A P value less than 0.05 was considered to be statistically significant. $* * *$ Indicates a $P$ value less than $0.00 I$. 
A
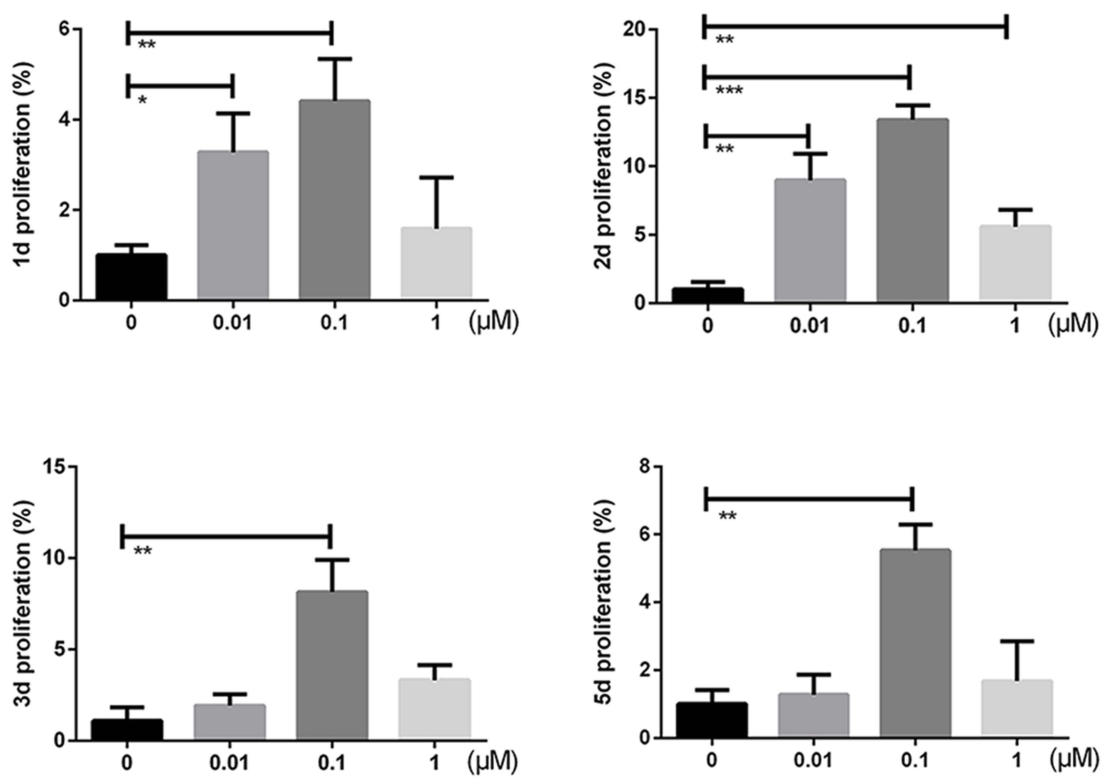

B

$\mathrm{Na}_{2} \mathrm{SeO}_{3} \quad \mathrm{O} \mu \mathrm{M}$

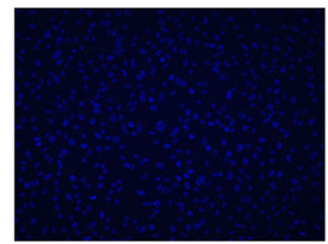

C

$\mathrm{Na}_{2} \mathrm{SeO}_{3}$

$0 \mu \mathrm{M}$

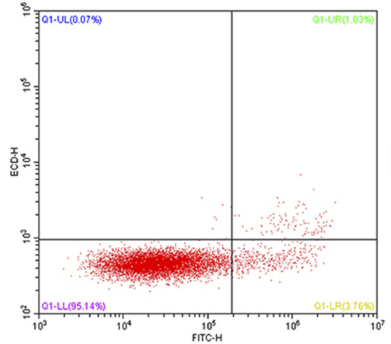

$1 \mu \mathrm{M}$

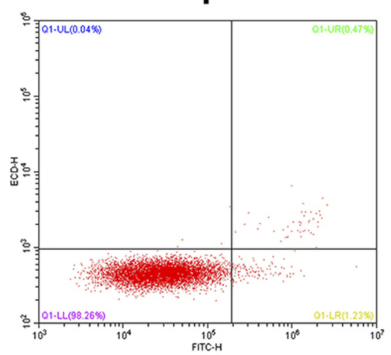

$0.01 \mu \mathrm{M}$

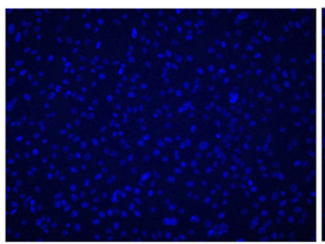

$0.01 \mu \mathrm{M}$
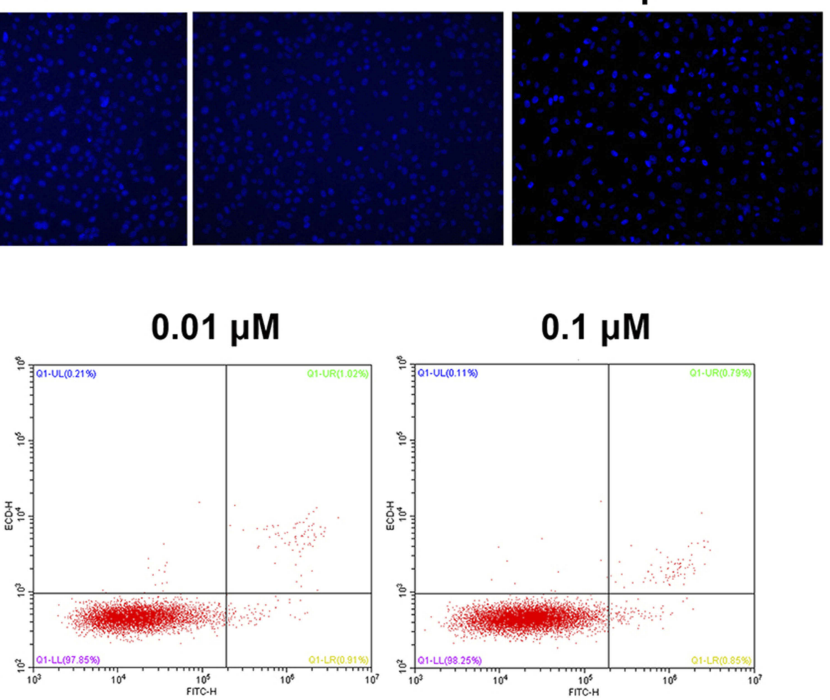

$0.1 \mu \mathrm{M}$

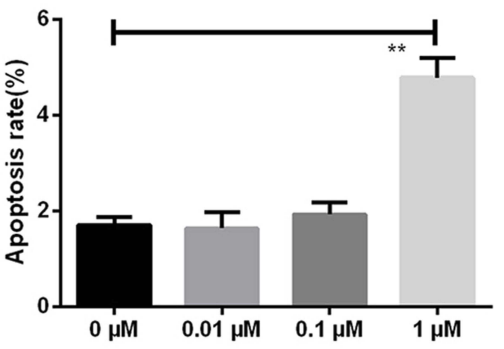

Figure 2 Proliferation and apoptosis of BMSCs. The effect of $\mathrm{Na}_{2} \mathrm{SeO}_{3}$ at different concentrations on the proliferation of BMSCs was assessed by the MTT assay (A). The effect of $\mathrm{Na}_{2} \mathrm{SeO}_{3}$ at different concentrations on BMSCs apoptosis in $\mathrm{BMSCs}$ was assessed after 48 hrs of treatment by Hoechst staining (B). The effect of $\mathrm{Na}_{2} \mathrm{SeO}_{3}$ at different concentrations on the apoptosis rate after $48 \mathrm{hrs}$ of treatment was assessed by flow cytometry (C). The values are from triplicate determinations. A $\mathrm{P}$ value less than 0.05 was considered to be statistically significant. *, ** and *** indicate $\mathrm{P}$ values less than $0.05,0.0 \mathrm{I}$, and $0.00 \mathrm{I}$, respectively. 


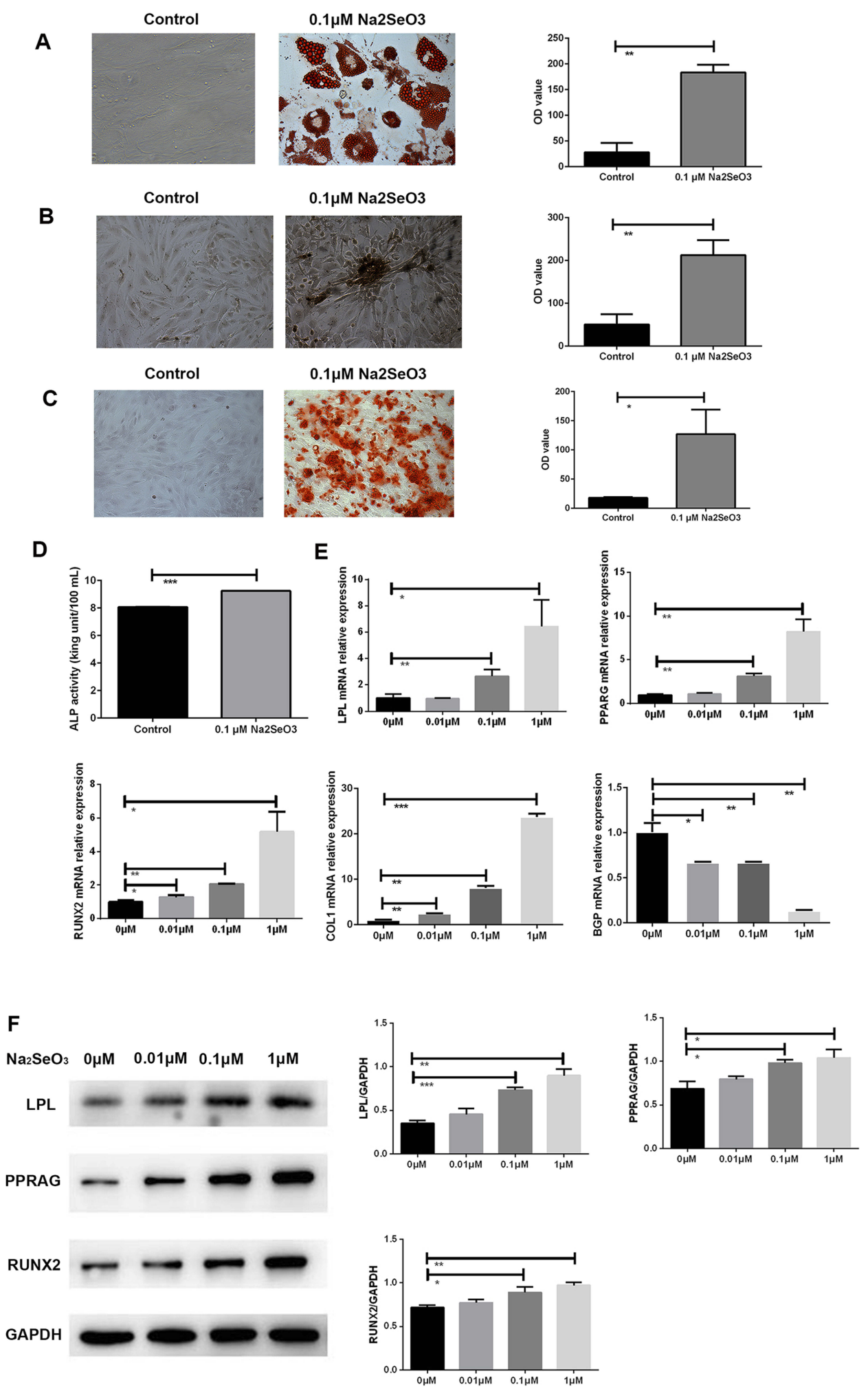

Figure 3 Detection of BMSCs osteogenesis and adipogenic differentiation. BMSCs from the fifth generation were in logarithmic growth phase and were incubated in adipogenic induction medium (containing $10 \%$ calf serum, $0.1 \mu \mathrm{mol} / \mathrm{L}$ dexamethasone, $0.25 \mathrm{mmol} / \mathrm{L}$ isobutyl methylxanthine, $100 \mu \mathrm{mol} / \mathrm{L}$ indomethacin, $6.25 \mu \mathrm{g} / \mathrm{mL}$ insulin, and $0.1 \mu \mathrm{M} \mathrm{Na}_{2} \mathrm{SeO}_{3}$ ) at $90 \%$ confluence. After 2 weeks of incubation, adipogenic differentiation was evaluated by oil red $\mathrm{O}$ staining (A). BMSCs from the fifth passage in logarithmic growth phase were incubated in osteogenesis induction medium (containing $10 \%$ calf serum, 50 mmol/L p-glycerin sodium phosphate, $0.1 \mu$ mol/L dexamethasone, $0.2 \mathrm{mmol} / \mathrm{L}$ vitamin $\mathrm{C}$, and $0.1 \mu \mathrm{M} \mathrm{Na} \mathrm{SeO}_{3}$ ) at about $60 \%$ fusion. The medium was changed once every 3 days. After 2 weeks of incubation, adipogenic differentiation was assessed by alkaline acid enzyme staining (B) and alizarin red S staining (C). ALP activity was detected by ELISA assay (D). RT-qPCR assay was used to detect the gene expression levels of the adipogenic factors LPL and PPRAG, and the osteogenic factors RUNX2, COL I, and BGP (E). The protein expression levels of the adipogenic factors $\mathrm{LPL}$ and PPRAG and the osteogenesis factor RUNX2 were detected by Western blotting $(\mathbf{F})$. The control groups were $\mathrm{BMSCs}$ incubated without $\mathrm{Na}_{2} \mathrm{SeO}_{3}$. The values from triplicate determinations. A P value less than 0.05 was considered to be statistically significant. *, ** and *** indicate $\mathrm{P}$ values less than $0.05,0.0 \mathrm{I}$ and $0.00 \mathrm{I}$, respectively. 
osteogenic and/or adipogenic differentiation of BMSCs can lead to hematological diseases such as aplastic anemia, ${ }^{22-25}$ emphasizing the importance of BMSCs both types of differentiation. After treatment with 0.1 $\mu \mathrm{M} \mathrm{Na} \mathrm{NeO}_{3}$, the BMSCs clearly appeared to transform into adipogenic (Figure 3A) and osteoblastic (Figure 3B, C and D) differentiated cells. In addition, after treatment with different concentrations of $\mathrm{Na}_{2} \mathrm{SeO}_{3}$, the expression of lipid factors (LPL and PPRAG) and osteogenic factors (RUNX2 and COL1) was significantly upregulated while the expression of BGP was markedly downregulated in a concentrationdependent manner(Figure 3D and E) (Figure 3E, Supplementary Material 1-4). This indicates that $\mathrm{Na}_{2} \mathrm{SeO}_{3}$ can promote osteogenic and adipogenic differentiation of BMSCs.

\section{The Effect Of $\mathrm{Na}_{2} \mathrm{SeO}_{3}$ On BMSC- Mediated Coagulation}

The coagulation cascade factor antigen derived from MSC is catalytically active and supports thrombin generation in vitro. MSCs have been added to citrated whole blood to enhance the platelet-mediated thrombus deposited in arterial walls. $^{26}$ Although the tissue factors expressed in BMSCs are effective coagulation activators, the process of cell differentiation affects the cell's ability to produce coagulation activators. $^{27}$ The coagulation time of mice blood decreased significantly in a concentration dependent manner after treatment with different cell number of BMSCs (Figure 4B). After the BMSCs were treated with different concentrations of $\mathrm{Na}_{2} \mathrm{SeO}_{3}$, the coagulation time of the blood of mice and rats increased significantly (Figure 4A). The detection of the hematopoietic factors of BMSCs showed that $\mathrm{Na}_{2} \mathrm{SeO}_{3}$ could significantly promote the expression of BMSCs hematopoietic factor SDF$1 \alpha$, GM-CSF, IL-7, IL-8, IL-11, and SCF in a concentration-dependent manner (Figure 4C). These data indicated that $\mathrm{Na}_{2} \mathrm{SeO}_{3}$ can inhibit the pro-coagulant effect of BMSCs and prolong the clotting time.

\section{Discussion}

There has been a major breakthrough in the application of stem cell therapy for the treatment of a variety of diseases due to in-depth understanding of multipotent stem cells. This has also enhanced the understanding of clinical uses of multi-potential stem cells, and the efficacy of stem cell therapy for the treatment of various diseases is being gradually recognized by the society. This also provides a potential and applicable therapeutic approach for utilizing stem cells to treat hematological diseases and even to improve the effect of blood transfusions. MSCs exhibit low expression levels of human leukocyte antigen (HLA) I class and do not express HLA II class antigens at all, facilitating allograft and xenotransplantation. ${ }^{28}$ MSCs inhibit the proliferation of $\mathrm{CD} 4+$ and $\mathrm{CD} 8+\mathrm{T}$ cells, decrease the production of interferon- $\gamma$ (IFN- $\gamma$ ) and cytotoxicity, induce the regulation of $\mathrm{T}$ cells, and inhibit the response of B cells. ${ }^{29}$ Most importantly, they decrease the chances of immune rejection. In this study, we investigated the morphology of the isolated BMSCs and the presence of cell surface antigens and compared them with the BMSCs identified previously. The results showed that the BMSCs were successfully isolated, and hence, we could perform the subsequent trials.

Few studies have evaluated the therapeutic effect and safety of selenium for biological uses. Using acute toxicity test, micronucleus test, sperm aberration test, and 30-day feeding test in mice, it was found that sodium selenite had different types of toxic effects on mice at different doses, including growth inhibition and cytotoxicity. ${ }^{30}$ Sodium selenite, containing $\mathrm{Se}^{+4}$, is an inorganic salt that can undergo redox reactions. Its biological effect varies based on its physical and chemical properties such as the expression of protein sparsely on the surface of cancer cells, prevention of the formation of non-enzymatic parafibrins covering cancer cells, and circumventing the recognition of lymphatic macrophages. ${ }^{31}$ Due to its ability to suppress the immune reactions, sodium selenite is considered as an inexpensive drug for the treatment and prevention of cancer. $^{32}$ However, when the concentration of sodium selenite is increased, it has opposite effect on the body. Therefore, care should be taken while deciding the concentration of sodium selenite based on the requirements of the disease it is meant to treat.

In this study, we confirmed the optimum concentration of $\mathrm{Na}_{2} \mathrm{SeO}_{3}$ required to induce proliferation and apoptosis in the BMSCs taking into consideration its toxic effects. We showed that while $0.1 \mu \mathrm{M}$ of $\mathrm{Na}_{2} \mathrm{SeO}_{3}$ can promote the proliferation of BMSCs, $1 \mu \mathrm{M}$ of $\mathrm{Na}_{2} \mathrm{SeO}_{3}$ promotes its apoptosis. Consequently, $0.1 \mu \mathrm{M} \mathrm{Na}_{2} \mathrm{SeO}_{3}$ was used as the optimum concentration for drug treatment in the subsequent trials.

In a previous study conducted on the bone marrow hematopoietic microenvironment in mutant mice, Zhang et $\mathrm{al}^{33}$ and Calvi et $\mathrm{al}^{34}$ found that the enlargement of 
A

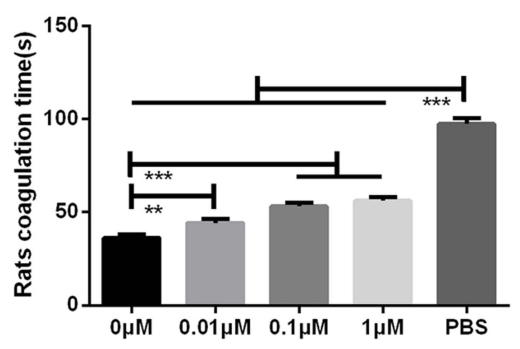

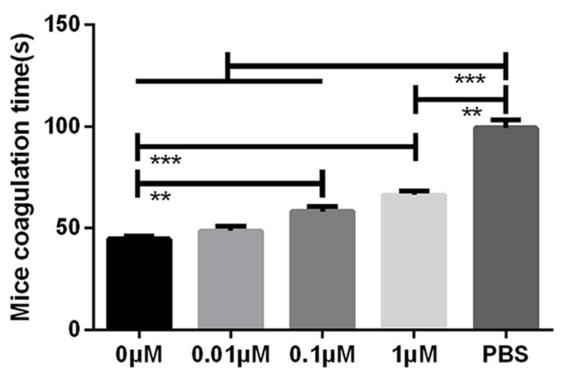

B

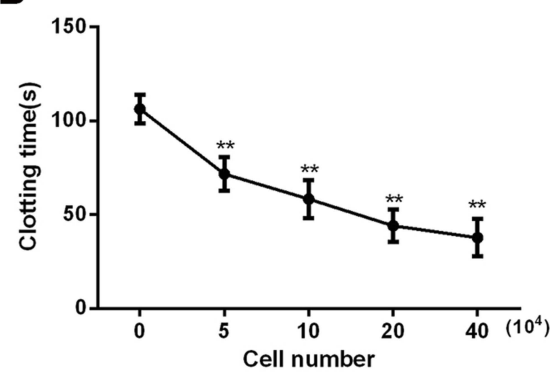

$c$

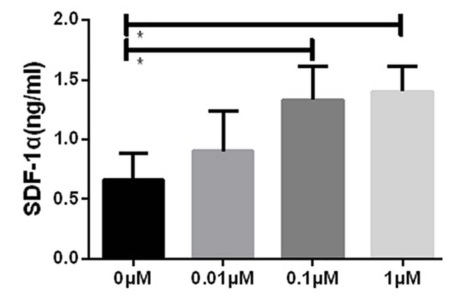

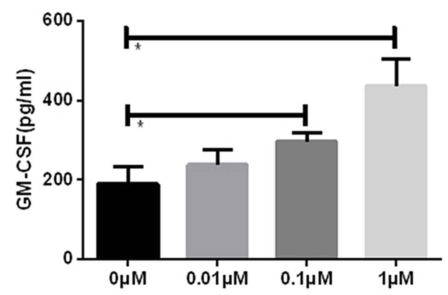
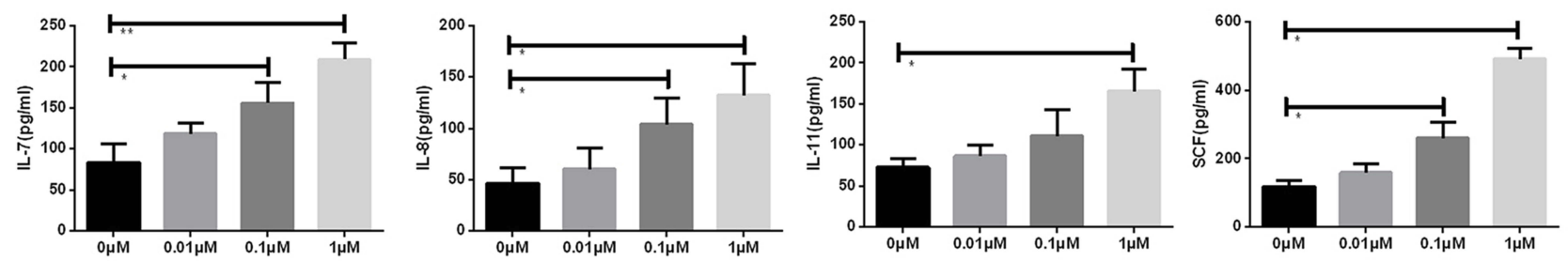

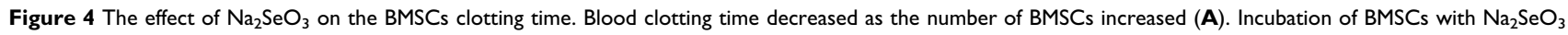
significantly prolonged coagulation time (B), which was associated with the increases in the expression levels of SDF-I $\alpha$, GM-CSF, IL-7, IL-8, IL-II, and SCF in the BMSCs and was dependent on the concentration of $\mathrm{Na}_{2} \mathrm{SeO}_{3}(\mathbf{C})$. The values are from triplicate determinations. A P value less than 0.05 was considered to be statistically significant. $*$, ** and *** Indicate $\mathrm{P}$ values less than $0.05,0.01$ and 0.001 , respectively.

trabecular bone due to the increase in the number of osteoblasts might also increase the number of hematopoietic stem cells in the bone marrow significantly. The study by Visnjic et al has shown that selective removal of mouse bone marrow osteoblasts led to a reversible decrease in the number of hematopoietic stem cells. ${ }^{35}$ Oxidative stress may play an important role in the development of osteoporosis by inhibiting osteogenic differentiation of MSCs. Pre-treatment with $\mathrm{Na}_{2} \mathrm{SeO}_{3}$ inhibited the activity of alkaline phosphatase, the expression of collagen I and osteocalcin gene, and the negative effect on the osteogenesis of BMSCs. In addition, $\mathrm{Na}_{2} \mathrm{SeO}_{3}$ preconditioning also inhibited the activation of extracellular signal-regulated kinase (ERK) induced by $\mathrm{H}_{2} \mathrm{O}_{2}$. These studies suggested that the inhibition of activation of oxidative stress and ERK by $\mathrm{Na}_{2} \mathrm{SeO}_{3}$ treatment promotes osteogenic differentiation of MSCs. ${ }^{36}$ Adipocyte differentiation of human MSCs depends on mitochondrial metabolism and reactive oxygen species (ROS). The upregulation of peroxisome proliferator-activated receptor-gamma (PPARG) promoted the adipocytic differentiation of human MSCs. ${ }^{37}$ Therefore, $\mathrm{Na}_{2} \mathrm{SeO}_{3}$ can be considered as an activator of the osteogenic and adipogenic differentiation of the BMSCs via regulation of the oxidative stress level. Our study results showed that $0.1 \mu \mathrm{M}$ of $\mathrm{Na}_{2} \mathrm{SeO}_{3}$ promoted osteogenic and adipogenic differentiation of BMSCs, which is consistent with previous studies.

MSCs are promising candidates for stem cell therapy as they are considered safe for clinical applications. However, minor side effects, including thromboembolism and immediate blood-mediated inflammatory response, do occur suggesting the effect of MSC infusion on hemostasis. ${ }^{38}$ Adipose-derived mesenchymal stem cells seem to possess more stable pro-coagulant 
activity than bone marrow-derived MSCs, which raises potential safety concerns for its systemic administration into patients with clotting diseases. There are donor variants available among different cell populations, and the coagulation conditions can also be determined by the culture conditions used for treatment. The cells must be routinely monitored during the preparation process to ensure that the required properties are retained before administering it into the patient. ${ }^{27}$ The preconditioning of BMSCs reduces the levels of tumor necrosis factor- $\alpha$ (TNF- $\alpha$ ), interferon- $\gamma$ (IFN- $\gamma$ ), interleukin-1 $\beta$ (IL-1 $\beta$ ), and interleukin-6 (IL-6) in the bacterial lipopolysaccharide (LPS)-induced-disseminated intravascular coagulation (DIC) model and increases the level of interleukin-10 (IL-10). It has also been seen that pretreatment with BMSCs can alleviate coagulation and organ dysfunction in LPS-induced DIC rat models by regulating the immune cells and pro-inflammatory cytokines. ${ }^{39,40}$ Previous studies focusing on plasma coagulation indicated the pro-coagulant and anti-coagulant activity of BMSCs. This study showed that BMSCs are dependent on their tissue of origin and inhibit platelet activation with the help of formation of adenosine from adenosine monophosphate due to the ecto-5'-nucleotidase activity of $\mathrm{CD} 73 .{ }^{38}$ Hence, $\mathrm{Na}_{2} \mathrm{SeO}_{3}$ may inhibit the coagulation mediated by BMSCs by affecting the differentiation of BMSCs. Consistent with previous studies, our study showed the inhibitory effect of $\mathrm{Na}_{2} \mathrm{SeO}_{3}$ on the BMSC-mediated coagulation process.

\section{Disclosure}

The authors report no conflicts of interest in this work.

\section{References}

1. Robey P. "Mesenchymal stem cells": fact or fiction, and implications in their therapeutic use. F1000Res. 2017;6. doi:10.12688/ f1000research.10955.1

2. Sipp D, Robey PG, Turner L. Clear up this stem-cell mess. Nature. 2018;561:455-457. doi:10.1038/d41586-018-06756-9

3. Fang B, Song Y, Li N, Li J, Zhao RC. Cotransplantation of haploidentical mesenchymal stem cells to reduce the risk of graft failure in a patient with refractory severe aplastic anemia. Acta Haematol. 2008;119:162-165. doi:10.1159/000134015

4. Jang MJ, Kim HS, Lee HG, et al. Placenta-derived mesenchymal stem cells have an immunomodulatory effect that can control acute graftversus-host disease in mice. Acta Haematol. 2013;129:197-206. doi:10.1159/000345267

5. Wu Y, Cao Y, Li X, et al. Cotransplantation of haploidentical hematopoietic and umbilical cord mesenchymal stem cells for severe aplastic anemia: successful engraftment and mild GVHD. Stem Cell Res. 2014;12:132-138. doi:10.1016/j.scr.2013.10.001
6. Wu KH, Tsai C, Wu HP, Sieber M, Peng CT, Chao YH. Human application of ex vivo expanded umbilical cord-derived mesenchymal stem cells: enhance hematopoiesis after cord blood transplantation. Cell Transplant. 2013;22:2041-2051. doi:10.3727/ 096368912 X663533

7. Kadekar D, Kale V, Limaye L. Differential ability of MSCs isolated from placenta and cord as feeders for supporting ex vivo expansion of umbilical cord blood derived CD34(+) cells. Stem Cell Res Ther. 2015;6:201. doi:10.1186/s13287-015-0114-1

8. Singer NG, Caplan AI. Mesenchymal stem cells: mechanisms of inflammation. Annu Rev Pathol. 2011;6:457-478. doi:10.1146/ annurev-pathol-011110-130230

9. Shi Y, Hu G, Su J, et al. Mesenchymal stem cells: a new strategy for immunosuppression and tissue repair. Cell Res. 2010;20:510-518. doi:10.1038/cr.2010.44

10. Hare JM, Fishman JE, Gerstenblith G, et al. Comparison of allogeneic vs autologous bone marrow-derived mesenchymal stem cells delivered by transendocardial injection in patients with ischemic cardiomyopathy: the POSEIDON randomized trial. JAMA. 2012;308:2369-2379. doi:10.1001/jama.2012.25321

11. Lee RH, Seo MJ, Reger RL, et al. Multipotent stromal cells from human marrow home to and promote repair of pancreatic islets and renal glomeruli in diabetic NOD/scid mice. Proc Natl Acad Sci U S A. 2006;103:17438-17443. doi:10.1073/pnas.0608249103

12. Moll G, Rasmusson-Duprez I, von Bahr L, et al. Are therapeutic human mesenchymal stromal cells compatible with human blood? Stem Cells. 2012;30:1565-1574. doi:10.1002/stem.1111

13. Tatsumi K, Ohashi K, Matsubara Y, et al. Tissue factor triggers procoagulation in transplanted mesenchymal stem cells leading to thromboembolism. Biochem Biophys Res Commun. 2013;431:203209. doi:10.1016/j.bbrc.2012.12.134

14. Rayman MP. Food-chain selenium and human health: emphasis on intake. $B r \quad J$ Nutr. 2008;100:254-268. doi:10.1017/ S0007114508939830

15. Okuno T, Honda E, Arakawa T, Ogino H, Ueno H. Glutathionedependent cell cycle G1 arrest and apoptosis induction in human lung cancer A549 cells caused by methylseleninic acid: comparison with sodium selenite. Biol Pharm Bull. 2014;37:1831-1837. doi:10.1248/bpb.b14-00453

16. Hosseinzadeh Anvar L, Hosseini-Asl S, Mohammadzadeh-Vardin M, Sagha M. The telomerase activity of selenium-induced human umbilical cord mesenchymal stem cells is associated with different levels of c-Myc and p53 expression. DNA Cell Biol. 2017;36:34-41. doi:10.1089/dna.2016.3411

17. Jakob F, Becker K, Paar E, Ebert-Duemig R, Schutze N. Expression and regulation of thioredoxin reductases and other selenoproteins in bone. Methods Enzymol. 2002;347:168-179. doi:10.1016/s0076-6879 (02)47015-2

18. Ebert-Dumig R, Schutze N, Jakob F. The thioredoxin reductase/ thioredoxin system in cells of the monocyte/macrophage pathway of differentiation. Biofactors. 1999;10:227-235. doi:10.1002/ biof. 5520100221

19. Schutze N, Fritsche J, Ebert-Dumig R, et al. The selenoprotein thioredoxin reductase is expressed in peripheral blood monocytes and THP1 human myeloid leukemia cells-regulation by 1,25-dihydroxyvitamin D3 and selenite. Biofactors. 1999;10:329-338. doi:10.1002/biof.5520100403

20. Ebert R, Ulmer M, Zeck S, et al. Selenium supplementation restores the antioxidative capacity and prevents cell damage in bone marrow stromal cells in vitro. Stem Cells. 2006;24:1226-1235. doi:10.1634/ stemcells.2005-0117

21. Monsel A, Zhu YG, Gudapati V, Lim H, Lee JW. Mesenchymal stem cell derived secretome and extracellular vesicles for acute lung injury and other inflammatory lung diseases. Expert Opin Biol Ther. 2016;16:859-871. doi:10.1517/14712598.2016.1170804 
22. Chen YH, Yeh FL, Yeh SP, et al. Myocyte enhancer factor-2 interacting transcriptional repressor (MITR) is a switch that promotes osteogenesis and inhibits adipogenesis of mesenchymal stem cells by inactivating peroxisome proliferator-activated receptor gamma-2. J Biol Chem. 2011;286:10671-10680. doi:10.1074/jbc.M110.199612

23. Hoshiba T, Kawazoe N, Chen G. The balance of osteogenic and adipogenic differentiation in human mesenchymal stem cells by matrices that mimic stepwise tissue development. Biomaterials. 2012;33:2025-2031. doi:10.1016/j.biomaterials.2011.11.061

24. Zhao J, Wang C, Song Y, Fang B. Arsenic trioxide and microRNA204 display contrary effects on regulating adipogenic and osteogenic differentiation of mesenchymal stem cells in aplastic anemia. Acta Biochim Biophys Sin (Shanghai). 2014;46:885-893. doi:10.1093/ abbs/gmu082

25. Chen J, Wei H, Xie B, Wang B, Cheng J, Cheng J. Endoplasmic reticulum stress contributes to arsenic trioxide-induced apoptosis in drug-sensitive and -resistant leukemia cells. Leuk Res. 2012;36:15261535. doi:10.1016/j.leukres.2012.08.018

26. Gleeson BM, Martin K, Ali MT, et al. Bone marrow-derived mesenchymal stem cells have innate procoagulant activity and cause microvascular obstruction following intracoronary delivery: amelioration by antithrombin therapy. Stem Cells. 2015;33:27262737. doi: $10.1002 /$ stem. 2050

27. Christy BA, Herzig MC, Montgomery RK, et al. Procoagulant activity of human mesenchymal stem cells. J Trauma Acute Care Surg. 2017;83:S164-S169. doi:10.1097/TA.0000000000001485

28. Rossignol J, Boyer C, Thinard R, et al. Mesenchymal stem cells induce a weak immune response in the rat striatum after allo or xenotransplantation. $J$ Cell Mol Med. 2009;13:2547-2558. doi:10.1111/j.1582-4934.2009.00657.x

29. Devaney J, Horie S, Masterson C, et al. Human mesenchymal stromal cells decrease the severity of acute lung injury induced by E. coli in the rat. Thorax. 2015;70:625-635. doi:10.1136/thoraxjnl-2015-206813

30. Wang X, Yang Y. Safety assessment and comparison of sodium selenite and bioselenium obtained from yeast in mice. Biomed Res Int. 2017;2017:3980972.doi:10.1155/2017/3980972.

31. Lipinski B. Sodium selenite as an anticancer agent. Anticancer Agents Med Chem. 2017;17:658-661. doi:10.2174/ 1871520616666160607011024
32. Tsai CF, Wu JY, Hsu YW. Protective effects of rosmarinic acid against selenite-induced cataract and oxidative damage in rats. Int $J$ Med Sci. 2019;16:729-740. doi:10.7150/ijms.32222

33. Zhang J, Niu C, Ye L, et al. Identification of the haematopoietic stem cell niche and control of the niche size. Nature. 2003;425:836-841. doi: $10.1038 /$ nature 02041

34. Calvi LM, Adams GB, Weibrecht KW, et al. Osteoblastic cells regulate the haematopoietic stem cell niche. Nature. 2003;425:841846. doi:10.1038/nature02040

35. Visnjic D, Kalajzic Z, Rowe DW, Katavic V, Lorenzo J, Aguila HL. Hematopoiesis is severely altered in mice with an induced osteoblast deficiency. Blood. 2004;103:3258-3264. doi:10.1182/blood-2003-11-4011

36. Liu H, Bian W, Liu S, Huang K. Selenium protects bone marrow stromal cells against hydrogen peroxide-induced inhibition of osteoblastic differentiation by suppressing oxidative stress and ERK signaling pathway. Biol Trace Elem Res. 2012;150:441-450. doi:10.1007/s12011-012-9488-4

37. Rhee YH, Moon JH, Mo JH, Pham T, Chung PS. mTOR and ROS regulation by anethole on adipogenic differentiation in human mesenchymal stem cells. BMC Cell Biol. 2018;19:12. doi:10.1186/ s12860-018-0163-2

38. Netsch P, Elvers-Hornung S, Uhlig S, et al. Human mesenchymal stromal cells inhibit platelet activation and aggregation involving CD73-converted adenosine. Stem Cell Res Ther. 2018;9:184. doi:10.1186/s13287-018-0936-8

39. Wang B, Wu S, Wang T, Ma Z, Liu K. Bone marrow-derived mesenchymal stem cells-mediated protection against organ dysfunction in disseminated intravascular coagulation is associated with peripheral immune responses. J Cell Biochem. 2017;118:31843192. doi:10.1002/jcb.25964

40. Wang B, Wu SM, Wang T, et al. Pre-treatment with bone marrowderived mesenchymal stem cells inhibits systemic intravascular coagulation and attenuates organ dysfunction in lipopolysaccharide-induced disseminated intravascular coagulation rat model. Chin Med J (Engl). 2012;125:1753-1759. doi:10.3760/cma.j.issn.0366-6999.2012.10.013

\section{Publish your work in this journal}

OncoTargets and Therapy is an international, peer-reviewed, open access journal focusing on the pathological basis of all cancers, potential targets for therapy and treatment protocols employed to improve the management of cancer patients. The journal also focuses on the impact of management programs and new therapeutic agents and protocols on patient perspectives such as quality of life, adherence and satisfaction. The manuscript management system is completely online and includes a very quick and fair peer-review system, which is all easy to use. Visit http://www.dovepress.com/ testimonials.php to read real quotes from published authors. 